\title{
Estudo taxonômico de Sapindaceae do litoral paraense
}

\author{
The taxonomic study of the Sapindaceae on the coastal of Pará
}

\author{
Camilo Veríssimo de Oliveira Barbosa ${ }^{1,2}$, Maria de Nazaré do Carmo Bastos ${ }^{1}$, \\ Julio dos Santos de Sousa ${ }^{1} \&$ Ana Paula Oliveira Cruz ${ }^{1}$
}

\begin{abstract}
Resumo
Este trabalho consiste no tratamento taxonômico de Sapindaceae Jusss. nas restingas do litoral paraense. A metodologia desse estudo compreendeu a análise do material proveniente de coletas e exsicatas dos herbários do Museu Goeldi (MG) e do Instituto Agronômico do Norte (IAN), além de literatura especializada. São apresentadas chave de identificação, descrições, distribuição geográfica, comentários e ilustrações das espécies. Foram encontradas oito espécies, distribuídas em seis gêneros: Cupania diphylla, Matayba discolor, M. guianensis, Paullinia pinnata, Serjania paucidentata, Talisia cerasina, T. veraluciana e Urvillea laevis. As espécies Urvillea laevis e Matayba discolor são novas ocorrências para a Amazônia brasileira. Serjania paucidentata é uma nova ocorrência para o estado do Pará. A formação floresta de restinga foi ecossistema que apresentou o maior número de táxons.
\end{abstract}

Palavras-chave: Amazônia, restinga, Sapindaceae, taxonomia.

\begin{abstract}
This study deals with the taxonomic treatment of the Sapindaceae Juss. on the coastal beach ridges of Pará. Methodology includes the analysis of botanical material from new collections and specimens of the Goeldi Museum (MG) and Agronomic Institute of the North (IAN) herberia, besides specialized literature. An identification key, descriptions, geographic distribution, comments and illustrations of species are provided. We described eight species, distributed in six genera: Cupania diphylla, Matayba discolor, M. guianensis, Paullinia pinnata, Serjania paucidentata, Talisia cerasina, T. veraluciana and Urvillea laevis. The species Urvillea laevis and Matayba discolor are new reports for the Brazilian Amazon. Serjania paucidentata is a new record for the state of Pará. The beach-ridge forest formation had the largest number of taxa.
\end{abstract}

Key words: Amazon, beach-ridge, Sapindaceae, taxonomy.

\section{Introdução}

As restingas, de acordo com a resolução $\mathrm{n}^{\circ} 261$, de 30 de junho de 1999, são definidas como um conjunto de ecossistemas que compreende comunidades vegetais florísticas e fisionomicamente distintas, situadas em terrenos arenosos de origem marinha, fluvial, lagunar, eólica ou combinações destas, de idade quaternária, em geral com solos pouco desenvolvidos (Conama 1999). Apesar das extensas áreas cobertas por restinga no litoral paraense, ainda são poucos os estudos taxonômicos nesse ecossistema, principalmente para as espécies de Sapindaceae.

A família Sapindaceae s.s. compreende ca. 1756 espécies e 136 gêneros (Silva 2011) e apresenta distribuição cosmopolita (Souza \& Lorenzi 2008). A família pertence à ordem Sapindales juntamente com as seguintes famílias: Anacardiaceae, Biebersteiniaceae, Burseraceae, Kirkiaceae, Nitrariaceae (Peganaceae e Tetradiclidaceae), Rutaceae, Meliaceae e Simaroubaceae (APG III 2009; Judd et al. 2008; Soltis et al. 2005; Silva 2011). No Brasil ocorrem 25 gêneros e 411 espécies, 4 subespécies e 7 variedades, distribuídas na Amazônia, Caatinga, Cerrado, Mata Atlântica, Pantanal (Somner et al. 2013).

Levando-se em conta a necessidade de estudos em áreas de restinga, este trabalho tem por objetivo o tratamento taxonômico de Sapindaceae das restingas do estado do Pará, fornecendo

\footnotetext{
${ }^{1}$ Museu Paraense Emílio Goeldi, MCT, Campus de Pesquisa, Coord. Botânica, Av. Perimetral 1901, Terra Firme, Belém, PA, 66017-970, Brasil.

${ }^{2}$ Autor para correspondência: camilo.verissimo@yahoo.com.br.
} 
informações para uma melhor identificação das espécies e subsídios aos planos de manejo das áreas de proteção ambiental deste ecossistema.

\section{Material e Métodos}

$\mathrm{O}$ estudo foi realizado no litoral paraense, que possui $500 \mathrm{~km}$ de extensão e situa-se entre a baía de Marajó e a foz do rio Gurupi, $46^{\circ}-48^{\circ} \mathrm{W}$ e $0^{\circ} 30^{\prime}-1^{\circ} \mathrm{S}$ (Furtado 1987). As restingas deste litoral apresentam seis formações vegetais distintas: halófila, psamófila reptante, brejo herbáceo, campo de dunas, formação aberta de moitas e floresta de restinga (Amaral et al. 2008).

A pesquisa foi baseada em material herborizado, incorporado no herbário do Museu Paraense Emílio Goeldi (MG) e da Empresa Brasileira de Pesquisa Agropecuária/Embrapa Amazônia Oriental (IAN), além de amostras coletadas no litoral paraense no período de outubro de 1990 a janeiro de 2012. A terminologia adotada para descrever a morfologia e os indumentos das estruturas vegetativas e reprodutivas foi baseada nos trabalhos de Acevedo-Rodrigues (1993, 2003), Barkley (1957), Ferrucci (2000), Hickey (1973), Lawrence (1973), Radford (1974), Rizzini (1977) e Somner (2001). A identificação do material coletado foi realizada através de consulta à bibliografia especializada, por análise comparativa com as exsicatas revisadas por especialistas e também por comparação do material tipo ou foto dos mesmos. As descrições morfológicas e suas respectivas ilustrações foram realizadas com o auxílio do estereomicroscópio, com câmara clara acoplada e por captura digital.

\section{Resultados e Discussão}

Sapindaceae Juss. Genera Plantarum 246. 1789.

Árvore, arbusto ou trepadeira escandente de até $20 \mathrm{~m}$ de altura. Ramos cilíndricos, acinzentados, vináceos ou castanho. Estípulas intrapeciolares ou interpeciolares, lanceoladas a falciformes, persistentes. Pecíolo decorrente, cilíndrico, alado ou não. Raque cilíndrica, decorrente, alada ou não. Folhas compostas, paripinadas ou imparipinadas, alternas. Folíolos discolores ou concolores, coriáceos a membranáceos, lanceolados, obovados, ovalados, elípticos, oblongos; nervuras secundárias 4-21 pares, venação broquidódroma, craspedódroma ou eucampdódroma. Inflorescência em panículas ou tirsos, axilares ou terminais. Flores unissexuadas ou bissexuadas, gamossépalas ou dialissépalas, dialipétalas ou gamopétalas. Cálice pentâmero ou tetrâmero; sépalas orbiculares, elípticas, deltóides, espatuladas, ovaladas ou obovadas. Corola pentâmera ou tetrâmera; pétalas oblongas, obovadas ou espatuladas. Estames 8, exsertos ou inclusos; filetes filiformes, eretos ou curvados; anteras basifixas ou dorsifixas, apiculadas ou não. Ovário unicarpelar ou tricarpelar; lóculos 3; estilete inteiro ou tripartido. Estigma inteiro, bipartido ou tripartido. Fruto bacáceo, capsular ou samarídio, apiculado ou não, estipitado, coriáceo ou cartáceo.

\section{Chave para identificação das espécies de Sapindaceae do litoral paraense}

1. Folhas imparipinadas.

2. Folíolos com margem serreada; venação craspedódroma; flores bissexuadas, cálice dialissépalo; antera dorsifixa; ovário unicarpelar 4. Urvillea laevis

2'. Folíolos com margem denteada ou inteira; venação broquidódroma ou eucampdódroma; flores unissexuadas; cálice gamossépalo; antera basifixa; ovário tricarpelar.

3. Ramos vináceos; folíolos concolores, ápice emarginado ou retuso, base obtusa; margem denteada; corola tetrâmera, pétalas com ápice arredondado; antera levemente pubescente; ovário elipsóide ou ovalado; estilete único 3. Paullinia pinnata

3'. Ramos castanho; folíolos discolores, ápice acuminado, base atenuada, margem inteira; corola pentâmera; pétalas com ápice agudo, truncado ou levemente emarginado; antera glabra; ovário obovado; estilete tripartido 7. Serjania paucidentata

1'. Folhas paripinadas.

4. Folíolos subopostos ou alternos.

5. Folíolos com ápice emarginado, obtuso ou arredondado; sépalas lanceoladas ou oblongas; ovário elipsóide; estigma bipartido 8. Cupania diphylla

5'. Folíolos com ápice atenuado ou acuminado; sépalas elípticas; ovário ovalado; estigma inteiro 
6. Arbusto; flores unissexuadas; pétalas com margem não ciliada; ovário tricarpelar 5. Talisia veraluciana

6'. Árvore; flores bissexuadas; pétalas com margem ciliada; ovário unicarpelar .... 6. Talisia cerasina 4'. Folíolos opostos.

7. Arbusto; folíolos obovados, ovalados, elípticos ou oblongos, ápice agudo, atenuado, emarginado ou retuso; nervuras secundárias 4-5 pares; pétalas obovadas; antera basifixa; ovário unicarpelar, obovado ou elipsóide 1. Matayba discolor

7’. Árvore; folíolos lanceolados, ápice acuminado; nervuras secundárias 6-15 pares; pétalas oblongas; antera dorsifixa; ovário tricarpelar, ovalado 2. Matayba guianensis

Descrição dos táxons

1. Matayba discolor (Spreng.) Radlk., Sitzungsber. Math.-Phys. Cl.Königl. Bayer. Akad. Wiss. München. 9: 630. 1879.

Fig. 1a-d

Arbusto de 1 a $4 \mathrm{~m}$ de altura. Ramos cilíndricos, acinzentados ou vináceos, sulcados. Pecíolo 0,5-4,4 cm compr., decorrente, cilíndrico, não alado. Raque 0,8-7,9 cm compr., decorrente, cilíndrica, não alada. Folíolos 2-19,1 cm compr., 1,8-6,6 cm larg., opostos, discolores, coriáceos, obovados, ovalados, elípticos ou oblongos, levemente estrigosos ou glabros, ápice agudo, emarginado, atenuado ou retuso; base cuneada, atenuada, assimétrica, margem inteira; nervuras secundárias 4-5 pares, venação broquidódroma. Inflorescência em panículas axilares. Flores unissexuadas. Cálice pentâmero, gamossépalo; sépalas 1-2 mm compr., deltóides, pubescentes; lobos 5, obtusos ou agudos. Corola pentâmera, gamopétala; pétalas 1-2 mm compr., obovadas, glabras, ápice truncado. Flores estaminadas; estames $8,1,5-5 \mathrm{~mm}$ compr., exsertos; antera $0,2-1$ $\mathrm{mm}$, basifixa, pubescente ou glabra, não apiculada. Flores pistiladas; ovário 2-6,5 $\mathrm{mm}$ compr., unicarpelar, ovalado ou elipsóide, pubescente; estilete inteiro; estigma inteiro. Fruto capsular 0,8-1,1 cm compr., 0,5-1,3 cm diâm., coriáceo, castanho-avermelhado, pubescente.

Distribui-se pela Venezuela e Brasil: Bahia, Espírito Santo, Maranhão, Alagoas, Pará, Paraná, Rio de Janeiro e Santa Catarina (Coelho 2008; Somner et al. 2013; Tropicos.org 2010).

Material selecionado: Maracanã, Ilha de algodoal, Praia da princesa, 12.IV.1991, fr., Bastos, M.N.C. et al. 766 (MG); restinga, 23.X.1990, fr., Bastos, M.N.C. et al. 679 (MG); 23.X.1990, fr., Bastos, M.N.C. et al. 626 (MG); 11.IV.1991, fr., Bastos, M.N.C. et al. 714 (MG); Maiandeua/Algodoal, dunas, III.1991, fr., Almeida, S. et al. 440 (MG); Ilha de Algodoal, dunas, 4.III.2000, fr., Lobato, C. et al. (MG); 21.II.1994. fl., Bastos, M.N.C. et al. 1541 (MG); 4.III.2000. fr., Lobato, C. et al. (MG), dunas, 2.II.1992, fr., Lobato, C. et al. 452 (MG); Praia da Marieta, floresta de restinga, 8.IX.1994, fl., Bastos, M.N.C. et al. 1815 (MG); Ilha de Maiandeua, floresta de restinga, 30.I.1988, fl., Araujo, D. et al. 8489 (MG); Ilha de Fortalezinha, floresta de restinga, 5-20.XII.1999, fl., Lobato, L.C.B. et al. 2478 (MG); dunas, 24.I.2012, fr., Gurgel, E.S.C. 855 (MG); 4.III.2000, fr., Lobato, L.C. et al. (MG); Salinópolis, floresta de restinga, 25.X.2005, fr., Rocha, A.E.S. et al. 310 (MG); Praia do Atalaia, dunas, 9.III.1989, fr., Carreira, L. et al. 1086 (MG); Ilha de Tarana, 8.IX.1994, fr., Bastos, M.N.C. et al. 1837 (MG).

De acordo com Coelho (2008), Matayba discolor apresenta as pétalas "obodeltóides", entretanto nas amostras do litoral paraense analisadas, as pétalas apresentaram-se obovadas. Nas restingas do Pará, M. discolor difere de M. guianensis principalmente por apresentar folíolos obovados a oblongos e 4-5 pares de nervuras secundárias.

2. Matayba guianensis Aubl.,Hist. Pl. Guiane 1: 331. 1775.

Fig. 1e-h

Árvore $4 \mathrm{~m}$ de altura. Ramos cilíndricos, acinzentados, sulcados. Pecíolo 6,8-9,9 cm compr., decorrente, cilíndrico, não alado, estrigoso. Raque 1-21,5 cm compr., cilíndrica, decorrente, não alada. Folíolos 5-9,8 cm compr., 1,5-2,8 cm larg., opostos, discolores, subcoriáceos, lanceolados, estrigosos ou híspidos, ápice acuminado, base cuneada ou arredondada, margem inteira; nervuras secundárias 6-15 pares, venação broquidódroma. Inflorescência em panículas axilares ou terminais. Flores unissexuadas. Cálice pentâmero, gamossépalo; sépalas, 1-3,5 mm compr., orbiculares, pubescentes; lobos 5, arredondados, pubescentes. Corola pentâmera, dialipétala; pétalas 1-2 mm compr., oblongas, glabras externamente, lanosas internamente, ápice truncado. Flores estaminadas; estames 8, 2-3,5 $\mathrm{mm}$ compr., exsertos; antera $0,3-1 \mathrm{~mm}$ compr., dorsifixa, glabra, não apiculada. Flores pistiladas; ovário 3-4 mm compr., tricarpelar, ovalado, densamente pubescente; estilete inteiro; estigma inteiro, pubescente. Fruto cápsular 1-1,8 cm compr., $0,5-2 \mathrm{~cm}$ diam., coriáceo, ferrugíneo, pubescente. 

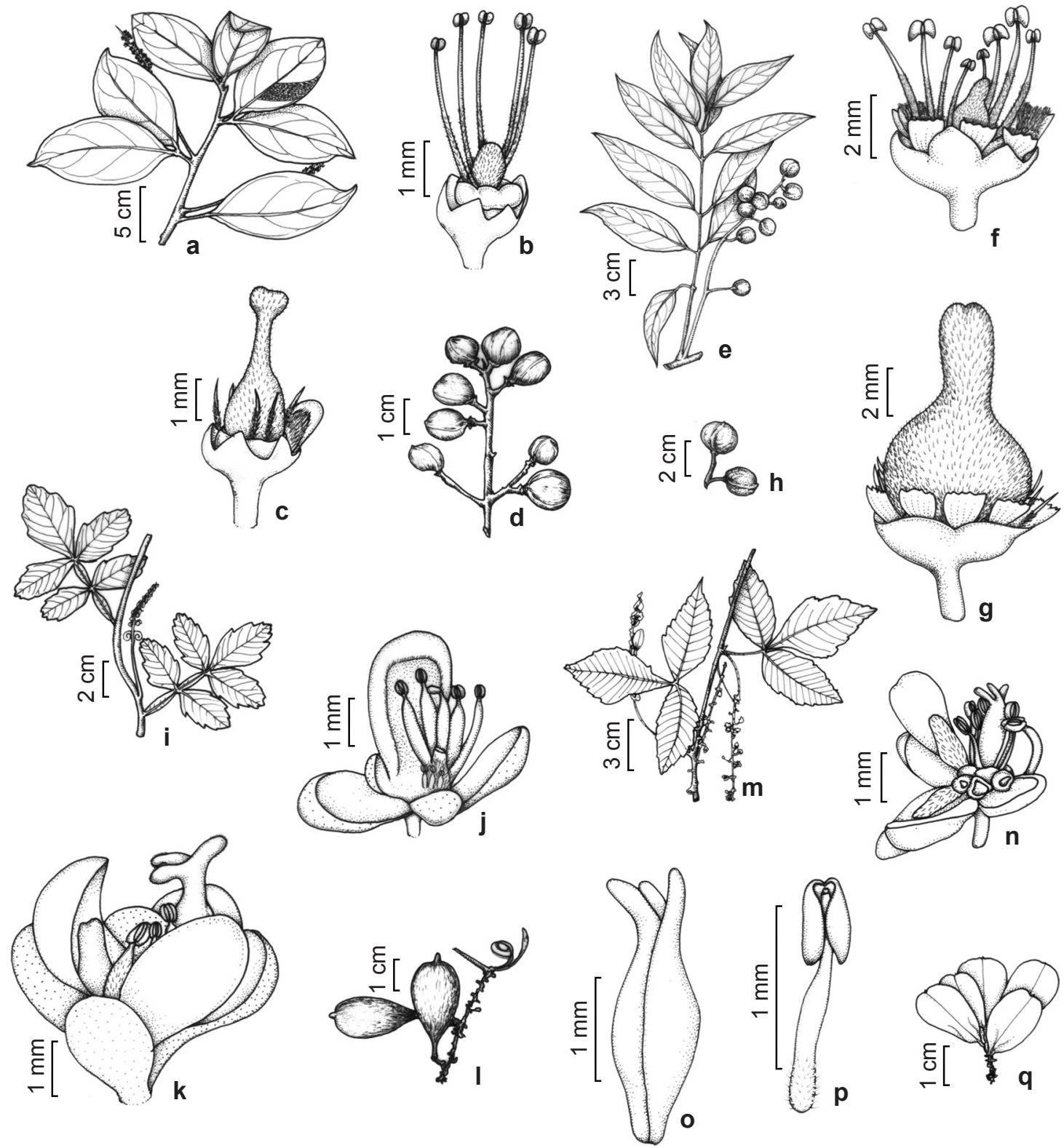

Figura 1 -a-d. Matayba discolor - a. hábito com inflorescência em panicula axilar; b. flor estaminada; c. flor pistilada; d. fruto capsular. e-h. Matayba guianensis - e. hábito com inflorescência em panicula axilar; f. flor estaminada; g. flor pistilada; h. fruto capsular. i-1. Paullinia pinnata - i. hábito com inflorescência em panicula axilar; j. flor estaminada; k. flor pistilada; 1. fruto capsular. m-q. Urvillea laevis - m. hábito com inflorescência em tirso axilar; $\mathrm{n}$. flor andrógina; o. gineceu; p. estame; q. fruto capsular.

Figure 1 - a-d. Matayba discolor - a. habit with inflorescence in axillary panicle; b. staminate flower; c. pistillate flower; d. fruit capsule type. e-h. Matayba guianensis - e. habit with inflorescence axillary panicle; f. staminate flower; g. pistillate flower; h. fruit capsule type. i-1. Paullinia pinnata - i. habit with inflorescence in axillary panicle; j. staminate flower; k. pistillate flower; 1 . fruit capsule type. m-q. Urvillea laevis - m. habit with inflorescence in axillary tirsus; $n$. androgyny flower o. gynoecium p. stamen q. fruit capsule type. 
Distribui-se pela Colômbia, Venezuela, Guiana Francesa, Peru, Brasil (Amazonas, Acre, Roraima, Rondônia, Pará, Mato Grosso, Goiás, Maranhão, Bahia, Minas Gerais, Espírito Santo, Alagoas, Ceará, Paraíba, Distrito Federal, Tocantins Mato Grosso do Sul, Paraná, Rio de Janeiro, Rio Grande do Sul, Santa Catarina e São Paulo) e Bolívia (Guarim Neto et al. 2000; Coelho 2008; Somner et al. 2013; Tropicos.org 2010).

Material selecionado: Maracanã, Praia da Marieta, floresta de restinga, 7.IX.1994, fl. e fr., Bastos, M.N.C. et al. 1791 (MG).

De acordo com Guarim Neto et al. (2000), Matayba guianensis apresenta os folíolos elípticos ou oblongo-lanceolados, contudo no material examinado foram encontrados somente folíolos lanceolados. Essa característica, juntamente com o ápice acuminado e a presença de 6-15 pares de nervuras secundárias ajudam a diferenciá-la de $M$. discolor nas restingas do Pará.

\section{Paullinia pinnata L., Sp. Pl.1: 366. 1753.}

Fig. 1i-1

Trepadeira escandente. Ramos cilíndricos, lenhosos, vináceos, levemente sulcados. Pecíolo 0,9-3,9 cm compr., cilíndrico, alado. Raque 1,1-2,5 $\mathrm{cm}$ compr., cilíndrica, alada. Folíolos 2,8-6,2 cm compr., 1,5-2,8 cm larg., alternos, concolores, membranáceos a coriáceos, elípticos ou oblongos, glabros, ápice emarginado ou retuso, base obtusa, margem dentada; nervuras secundárias 6-9 pares, venação eucampdódroma. Inflorescência em paniculas axilares, tirsóides. Flores unissexuadas. Cálice tetrâmero, gamossépalo; sépalas $0,5-3,5 \mathrm{~mm}$ compr., ovaladas ou obovadas, glabras; lobos 4, arredondados. Corola tetrâmera, dialipétala; pétalas $2-3,5 \mathrm{~mm}$ compr., oblongas, glabras, ápice arredondado. Flores estaminadas; estames 8,2-4 mm compr., exsertos; antera $1 \mathrm{~mm}$ compr., basifixa, levemente pubescente, não apiculada. Flores pistiladas; ovário 4-5 mm compr., tricarpelar, elipsóide ou ovalado, pubescente; estilete inteiro; estigma tripartido. Fruto capsular 3-3,6 cm compr., 1-1,5 cm larg., coriáceo, avermelhado ou ferrugíneo, glabro.

Material selecionado: Viseu, floresta de restinga, 19.V.1998, fl. e fr., Lobato, L.C.B. et al. 2105 (MG).

Distribui-se pelo Caribe, Equador, Estados Unidos, México, Guatemala, Honduras, Madagascar, Republica Dominicana, Porto Rico, Tanzânia, Guiana Francesa, Guiana, Venezuela, Suriname, Brasil (Amapá, Amazonas, Rondônia, Pará, Mato Grosso, Goiás, Maranhão, Piauí, Ceará,
Alagoas, Bahia, Mato Grosso do Sul, Pernambuco, Sergipe e Tocantins) e Bolívia (Standley 1949; Somner et al. 2013; Tropicos.org 2010).

Paullinia pinnata pode ser confundida com Serjania paucidentata no litoral paraense por apresentar raque alada, entretanto é facilmente reconhecida por apresentar folíolos elípticos, ápice emarginado ou retuso, base obtusa, margem dentada, corola tetrâmera, estilete único e estigma tripartido. Com relação as demais espécies de Sapindaceae das restingas do Pará, P. pinnata difere-se pelo pecíolo alado, que juntamente com as folhas biternadas ou ternadas e as margens denteadas, formam um conjunto de características que subsidiam na separação da espécie. A espécie pode ser encontrada na formação floresta de restinga.

\section{Urvillea laevis Radlk., Atti Congr. Bot. Firense} 63. 1874 (1876).

Fig. $1 \mathrm{~m}-\mathrm{q}$

Trepadeira escandente. Ramos cilíndricos, acinzentados, não sulcados. Pecíolo 0,3-0,9 $\mathrm{cm}$ compr., decorrente, cilíndrico, não alado. Raque $9 \mathrm{~cm}$ compr., cilíndrica, decorrente, não alada. Folíolos 2-6,2 cm compr., 0,4-3,8 cm larg., subopostos, discolores, membranáceos, elípticos, ovalados ou oblongos, glabros, ápice atenuado ou agudo, base atenuada, margem serreada; nervuras secundárias 7-17 pares, venação craspedódroma. Inflorescências em tirsos, axilares. Flores bissexuadas. Cálice pentâmero, dialissépalo; sépalas $0,8-2,5 \mathrm{~mm}$ compr., espatuladas, glabras, ápice agudo. Corola pentâmera, dialipétala; pétalas 2-3 mm compr., espatuladas, glabras, ápice emarginado. Estames com 8, 1,5-2,5 mm compr., exsertos; antera $0,5 \mathrm{~mm}$ compr., dorsifixa, glabra, não apiculada. Ovário 2,6-5 mm compr., unicarpelar, elipsóide, glabro; estilete inteiro; estigma tripartido. Fruto cápsular 1,8-2,6 cm compr., 1,3-1,5 cm larg., cartáceo, castanho, glabro ou pubescente.

Material selecionado: Salinas, dunas, 17.VII.1907, fl. e fr., Ducke, A. 881 (MG).

Distribui-se pelo Brasil (Pará, Distrito Federal, Ceará, Pernambuco, Bahia, Minas Gerais, Espírito Santo, Mato Grosso do Sul, Rio de Janeiro, São Paulo e Paraná) e Bolívia (Guarim Neto et. al. 2000; Somner et al. 2013; Tropicos.org 2010).

Nas restingas do Pará, Urvillea laevis diferencia-se das demais espécies estudadas por apresentar folíolos com margem serreada, venação craspedódroma e cálice dialissépalo. A espécie ocorre em formação de dunas, sendo esta uma nova ocorrência para o estado do Pará. 
5. Talisia veraluciana Guarim, Acta Amazonica 9(2): 239. 1979.

Fig. 2a-d

Arbusto de $3 \mathrm{~m}$ de altura. Ramos cilíndricos, castanho, sulcados. Pecíolo 0,4-0,9 cm compr., decorrente, cilíndrico, não alado. Raque 7,5-14 cm compr., decorrente, cilíndrica, não alada. Folíolos 4,9-9,4 cm compr., 2,2-3,5 cm larg., alternos ou subopostos, discolores, coriáceos, elípticos, lanceolados, glabros, estrigosos ou híspidos, ápice emarginado ou acuminado, base cuneada ou obtusa, margem inteira; nervuras secundárias 10-12 pares, venação broquidódroma. Inflorescência em panículas axilares ou terminais. Flores unissexuadas. Cálice pentâmero, gamossépalo; sépalas 2,5-7,1 mm compr., elípticas, glabras; lobos 5 , agudos, glabros. Corola pentâmera, dialipétala; pétalas 2,5-8 $\mathrm{mm}$ compr., obovadas, oblongas, glabras, ápice agudo ou arredondado. Flores estaminadas; estames 8,2-5 mm compr., inclusos; antera $0,5-1 \mathrm{~mm}$ compr., basifixa, levemente pubescente, apiculada. Flores pistiladas; ovário 5-6 mm compr., tricarpelar, ovalado, pubescente; estilete inteiro; estigma inteiro, pubescente. Fruto bacáceo $2,5 \mathrm{~cm}$ compr., $1,7 \mathrm{~cm}$ diam., coriáceo, castanho, rugoso, pubescente.

Material selecionado: Maracanã, Ilha de algodoal, Praia da princesa, floresta de restinga, 21.III.1994, fl. e fr., Bastos, M.N. et al.1590 (MG).

Distribui-se pela Colômbia e Brasil (Amapá, Amazonas, Pará e Mato Grosso) (Guarim Neto 1979; Somner et al. 2013; Tropicos.org 2010).

No litoral paraense, Talisia veraluciana caracteriza-se por ser a única espécie que possui anteras apiculadas. A espécie pode ser distinta de T. cerasina (Benth.) Radlk. por apresentar hábito arbustivo, brácteas oblongas, flores unissexuadas, pétalas com margem não ciliada, ovário tricarpelar. Esta espécie pode ser encontrada nas formações de restingas da Praia da Princesa.

6. Talisia cerasina (Benth.) Radlk., Sitzungsber. Math.-Phys. Cl. Königl. Bayer. Akad. Wiss. München 8(3): 347-348. 1878.

Fig. 2e-i

Árvore de 3-20 m de altura. Ramos cilíndricos, acinzentados, sulcados. Pecíolo 0,2-0,5 cm compr., decorrente, cilíndrico, não alado. Raque 9,4-14,2 cm compr., decorrente, cilíndrica, não alada. Folíolos 10,6-16,2 cm compr., 2,8-4,7 cm larg., subopostos, discolores, coriáceos, lanceolados, glabros; ápice atenuado, acuminado ou agudo; base atenuada; margem inteira; nervuras secundárias 9-21 pares, venação broquidódroma. Inflorescência em panículas axilares ou terminais. Flores bissexuadas. Cálice pentâmero, gamossépalo; sépalas 2-3,5 mm de compr., orbiculares, pubescentes externamente e glabras internamente; lobos 5, obtusos. Corola pentâmera, dialipétala; pétalas 5-7 $\mathrm{mm}$ compr., oblongas, glabras, ápice obtuso. Estames 8,5-5,5 $\mathrm{mm}$ compr., inclusos; antera 1-2 $\mathrm{mm}$ compr., basifixa, glabra, não apiculadas. Ovário $3-5 \mathrm{~mm}$ compr., unicarpelar, ovalado, pubescente; estilete inteiro; estigma inteiro. Fruto bacáceo 1,1-2 cm compr., 0,5-0,8 cm larg., coriáceo, preto, pubescente. Material selecionado: Bragança, floresta de restinga, 27.XII.1955, fl., Bordallo, A. (MG).

Distribui-se pela Costa Rica; Panamá, Colômbia, Venezuela, Equador, Peru, Brasil (Amazonas, Acre, Rondônia, Pará, Pernambuco, Bahia, Minas Gerais e Espírito Santo) e Bolívia. (Somner et al. 2013; Tropicos.org 2010).

Nas restingas do litoral paraense, Talisia cerasina caracteriza-se por apresentar folíolos com ápice atenuado. Essa característica, juntamente com as brácteas lanceoladas, flores andróginas, pétalas com margem ciliada e ovário unicarpelar, ajudam a diferenciá-la de T.veraluciana. Esta espécie ocorre nas formações de floresta de restinga.

7. Serjania paucidentata DC. Seem. Bot. Voy. Herald 92. 1853.

Fig. $2 \mathrm{j}-\mathrm{m}$

Trepadeira escandente. Ramos cilíndricos, castanho, sulcados. Pecíolo 3,7-4,9 cm compr., decorrente, cilíndrico, não alado. Raque 2,5-3,3 cm compr., cilíndrica, alada. Folíolos 1,5-7,4 cm compr., 1,1-3,6 cm larg., subopostos ou opostos, discolores, subcoriáceos, elípticos ou oblongos, glabros, ápice acuminado, base atenuada, margem inteira; nervuras secundárias 5-11 pares, venação broquidódroma. Inflorescência em panículas axilares. Flores unissexuadas. Cálice tetrâmero, gamossépalo, sépalas $2-3,5 \mathrm{~mm}$ compr., obovadas ou oblongas, pubescentes externamente e glabra internamente, lobos 4, agudos. Corola pentâmera, dialipétala; pétalas 3-5 mm compr., oblongas, obovadas, glabras; ápice agudo, truncado ou levemente emarginado. Flores estaminadas; estames $8,2,5-5 \mathrm{~mm}$ compr., exsertos; antera $0,5-1 \mathrm{~mm}$, basifixa, glabra, não apiculada. Flores pistiladas; ovário $4-5,5$ $\mathrm{mm}$ compr., tricarpelar, obovado ou levemente oblongo, tomentoso; estilete tripartido; estigma tripartido. Fruto samarídio 1-2,5 cm compr., 1,1-1,6 cm larg., membranáceo, castanho claro, levemente pubescente. 

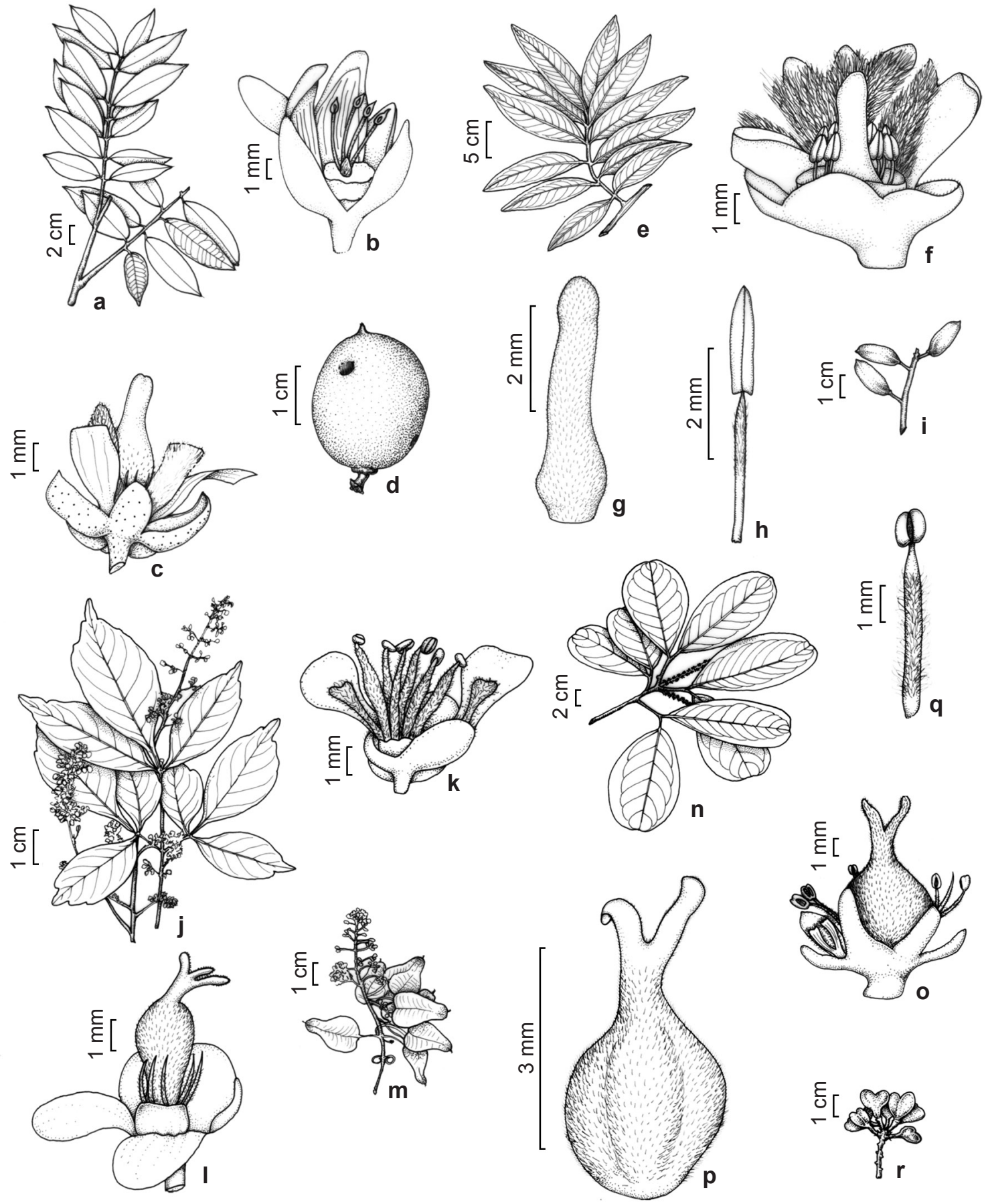

Figura 2 - a-d. Talisia veraluciana - a. hábito com foliolos elipticos ou lanceolados; b. flor estaminada; c. flor pistilada; d. fruto bacáceo. e-i. Talisia cerasina - e. hábito com foliolos lanceolados; f. flor andrógina; g. gineceu; h. estame; i. fruto bacáceo. j-m. Serjania paucidentata - j. hábito com inflorescência em paniculas axilares; k. flor estaminada; 1. flor pistilada; $\mathrm{m}$. fruto samaridio. n-r. Cupania diphylla - n. hábito com inflorescência em panicula terminal; o. flor andrógina; p. gineceu; q. estame; r. fruto capsular.

Figure 2 - Talisia veraluciana - a. habit with elliptical or lanceolate, leaflets; b. staminate flower; c. pistillate flower; d. fruit duproid type. e-i. Talisia cerasina - e. habit with lanceolate, leaflets; f. androgyny flower g. gynoecium h. stamen i. fruit duproid type. j-m. Serjania paucidentata - j. habit with inflorescence in axillary panicle; k. staminate flower; 1 . pistillate flower; m. fruit samara type. n-r. Cupania diphylla $-\mathrm{n}$. habit with inflorescence terminal panicle; o. androgyny flower p. gynoecium q. stamen r. fruit capsule type. 
Material selecionado: Maracanã, Ilha de Algodoal, dunas, 1.VII.1992, fl. e fr., Lobato, L.C.B. et al. 490 (MG).

Distribui-se pelo Brasil: Acre, Ceará e Minas Gerais (Somner et al. 2013; Tropicos.org 2010).

No litoral paraense, Serjania paucidentata destaca-se por apresentar folíolos biternados, ovalados e raque alada, características diagnósticas para seu reconhecimento no ambiente de restinga. A espécie é uma nova ocorrência para o estado do Pará.

8. Cupania diphylla Vahl, Eclog. Amer. 3:9. 1807.

Fig. $2 n-r$

Arbusto ou árvore 3-5 m de altura. Ramos cilíndricos, acinzentados, não sulcado. Pecíolo 0,4-17,9 cm compr., decorrente, cilíndrico, não alado. Raque 1,1-5 cm compr., cilíndrica, decorrente, não alada. Folíolos 4,1-20,2 cm compr., 1,2-9,9 cm larg., alternos, discolores, cartáceos ou coriáceos, elípticos ou obovados, glabros ou estrigosos; ápice emarginado, obtuso ou arredondado; base atenuada, cuneada ou assimétrica; margem inteira; nervuras secundárias 5-13 pares, broquidódromas. Inflorescência em paniculas axilares ou terminais. Flores bissexuadas. Cálice pentâmero, gamossépalo; sépalas 5-6,5 $\mathrm{mm}$ compr., lanceoladas ou oblongas, pilosas; lobos 5, agudos. Corola pentâmera, dialipétala, pétalas 1,5-4 mm compr., oblongas ou obovadas, pubescentes externamente e glabras internamente, ápice agudo ou truncado. Estames 8, 1,5-3,5 mm compr., exsertos; antera 0,5-1 mm compr., basifixa, glabra, levemente pubescente, não apiculada. Ovário 5-6 mm compr., tricarpelar, elipsóide, híspido; estilete inteiro; estigma bipartido. Fruto cápsular 0,9-1,3 cm compr., 0,5-1,5 cm larg., cartáceo, castanho escuro, pubescente.

Material selecionado: Maracanã, Ilha de Algodoal, Praia da princesa, floresta de restinga, 20.XII.1993, fl., Bastos, M.N.C. et al. 1518 (MG); 19-25.VIII.1994, fl., Bastos, M.N.C. et al.1732 (MG); dunas, 4.II.1992, fl., Lobato, L.C.B. et al. 463 (MG); Ilha do Marco, dunas, 12.I.1992, fr., Bastos, M.N.C. et al.1145 (MG); Ilha de Maiandeua, floresta de restinga, 18.XII.1993, fl., Bastos, M.N.C. et al.1474 (MG); floresta de restinga, 21.XII.1993, fl., Bastos, M.N.C. et al.1485 (MG); Ilha de Fortalezinha, floresta de restinga, 5-20.XII.1999, fl., Lobato, L.C.B. et al. 2491 (MG); Praia da Marieta, restinga, 7.IX.1994, fl., Bastos, M.N.C. et al.1793 (MG).

Distribui-se pelo Suriname, Guiana Francesa, e Brasil (Amapá, Amazonas, Acre, Pará e Maranhão) (Somner et al. 2013; Tropicos.org 2010).

Cupania diphylla pode ser facilmente reconhecida nas restingas do litoral paraense por ser a única que apresenta estigma bipartido. Esta característica, associada ao ápice foliar emarginado, obtuso ou arredondado; as sépalas lanceoladas ou oblongas e ao ovário elipsóide, são diagnósticas na identificação desta espécie.

Os principais caracteres utilizados para a separação das espécies de Sapindaceae da restinga paraense foram o tipo de venação broquidódroma, craspedódroma e eucampdódroma e a filotaxia das folhas compostas paripinadas ou imparipinadas, folíolos opostos, subopostos ou alternos. Os gêneros Matayba e Talisia foram os mais representativos, com duas espécies cada. As espécies Serjania paucidentata e Urvillea laevis são novas ocorrências para o estado do Pará. As espécies Matayba discolor e Urvillea laevis são novas ocorrências à região Amazônica brasileira. $\mathrm{Na}$ restinga paraense, Cupania diphylla e $M$. discolor foram as mais abrangentes, ocorrendo desde campo de dunas até floresta de restinga. A formação floresta de restinga foi a mais representativa, apresentando seis das oito espécies registradas ao longo do litoral do estado do Pará.

\section{Agradecimentos}

Os autores agradecem ao Museu Paraense Emílio Goeldi (MPEG) e ao Conselho Nacional de Desenvolvimento Científico e Tecnológico (CNPq) a concessão da bolsa e apoio logístico para a realização deste trabalho. E a todas as pessoas que contribuíram direta ou indiretamente para que este trabalho fosse realizado.

\section{Referências}

Acevedo-Rodrigues, P. 1993. Systematics of Serjania (Sapindaceae), part I: a revision of Serjania sect. Platycoccus. Memoirs of the New York Botanical Garden 67: 1-93.

Acevedo-Rodrigues, P. 2003. Melicocceae (Melicoccus and Talisia) Sapindaceae. Flora Neotropica Monograph 87: 1-178.

Amaral, D.D.; Prost, M.T.; Bastos, M.N.C; Costa Neto, S.V. \& Santos, J.U.M. 2008. Restingas do litoral amazônico, estados do Pará e Amapá, Brasil. Boletim do Museu Paraense Emílio Goeldi 3: 35-67.

APG III. 2009. An update of the Angiosperm Phylogeny Group classification for the orders and families of flowering plants: APG III. Botanical Journal of the Linnean Society 161: 105-121.

Barkley, F.A. 1957. Sapindaceae of Southern América. Lilloa 28: 111-179.

Coelho, R.L.G. 2008. Estudos taxonômicos em Matayba Aubl. Sect. Matayba (Sapindaceae). Dissertação 
de Mestrado. Universidade Estadual de Campinas, Campinas. 170p.

CONAMA n 261, de 30 de junho de 1999. Disponível em < http://www.lei.adv.br/261-99.htm>. Acesso em 21 Mai 2013.

Ferrucci, M.S. 2000. Revisón de los géneros Cardiospermum y Urvillea para el neotrópico (Sapindaceae). Tese de Doutorado. Universidade Nacional de Córdoba, Córdoba. 262p.

Furtado, L.G. 1987. Curralistas e redeiros de Marudá: pescadores do litoral do Pará. Museu Paraense Emílio Goeldi, Belém. 366p.

Guarim Neto, G. 1979. Estudos em Sapindaceae I. Novas espécies de Talisia Aublet para o Brasil. Acta Amazônica 9: 233-239.

Guarim Neto, G.; Santana, S.R. \& Silva, J.V.B da, 2000. Notas etnobotânicas de espécies de Sapindaceae Jussieu. Acta Botanica Brasilica 14: 327-334.

Hickey, L.J. 1973. Classification of the arquitecture of dicotyledonous leaves. American Journal of Botany 60: 17-33.

Judd, W.S.; Campbell, C.S.; Lellogg, E.A.; Stevens, P.F. \& Donogue, M.J. 2008. Plant systematics: a phylogenetic approach. $3^{\text {rd }}$ ed. Sinauer Associates, Stamford. Pp. 429-440.

Lawrence, G.H.M. 1973. Taxonomy of vascular plants. Macmillan, New York. Pp. 767-809.

Radford, A.E. et al. 1974. Vascular plant systematics. Harper \& Row, New York. 891p.
Rizzini, C.T. 1977. Sistematização terminológica da folha. Rodriguésia 29: 103-125.

Silva, K.F. 2011. Sapindaceae na Serra do Cipó, Minas Gerais, Brasil. Dissertação de Mestrado. Universidade de São Paulo, São Paulo. 148p.

Soltis, D.E.; Soltis, P.S.; Endress, P.K. \& Chase, M.W. 2005. Phylogeny and evolution of angiosperms. Smithsonian Books, Washington, DC. 370p.

Somner, G.V. 2001 Paullinia L. (Sapindaceae): morfologia, taxonomia e revisão de Paullinia sect. Phygoptilon. Tese de Doutorado. Universidade de São Paulo, São Paulo.

Somner, G.V.; Ferrucci, M.S.; Acevedo-Rodríguez, P.; Coelho, R.L.G. 2013. Sapindaceae. In: Lista de espécies da flora do Brasil. Jardim Botânico do Rio de Janeiro. Disponível em $<$ http://floradobrasil. jbrj.gov.br/jabot/floradobrasil/FB216>. Acesso em 15 Abr 2013.

Souza, V.C. \& Lorenzi, H. 2008. Botânica sistemática: guia ilustrado para identificação das famílias de fanerógamas nativas e exóticas no Brasil, baseado em APG II. Instituto Plantarum, Nova Odessa. 704p.

Standley, P.C. \& Steyermark, J.A. 1949. Sapindaceae. In: Standley, P.C. \& Steyermark, J.A. (eds.). Flora of Guatemala - Part VI. Fieldiana, Bot. 24: 234-316.

Tropicos.org. 2010. Missouri Botanical Garden. Disponível em <http://www.mobot.mobot.org/ W3T/Search/vast.html>. Acesso em 10 Set 2010. 